\title{
Hydrogenation of non-polar Fraction of Bio-oil from Co-pyrolysis of Corn Cobs and Polypropylene for Bio-diesel Production
}

\author{
Dijan Supramono ${ }^{1}$, Justin Edgar ${ }^{1}$, Setiadi $^{1}$, and Mohammad Nasikin ${ }^{1 *}$ \\ ${ }^{1}$ Department of Chemical Engineering, Faculty of Engineering, Universitas Indonesia, Depok 16424, Indonesia
}

\begin{abstract}
Bio-diesel was synthesized by hydrogenating the non-polar fraction of the bio-oil produced from the co-pyrolysis between corncobs and polypropylene. Co-pyrolysis of corn cobs and polypropylene was conducted in a stirred tank reactor at heating rate of $5^{\circ} \mathrm{C} / \mathrm{min}$ and maximum temperature of $500^{\circ} \mathrm{C}$ to attain synergetic effect in non-polar fraction yield where polypropylene served as a hydrogen donor and oxygen sequester so that the oxygenate content in the biofuel product reduced. Stirred tank reactor configuration allowed phase separation between non-polar and polar (oxygenate) compounds in the bio-oil. Hydrogenation reaction of the separated non-polar phase, which contained alkenes, was carried out in a pressured stirred tank reactor using a $\mathrm{NiMo} / \mathrm{C}$ catalyst in order to reduce the alkene content in the bio-oil. The aim of the present work is to reduce the alkene content in the separated non-polar fraction of bio-oil by catalytic hydrogenation to obtain biofuel with low alkene content and viscosity approaching to that of diesel fuel. To quantify effect of the pressure on the alkene composition, the experiment was done at $\mathrm{H}_{2}$ initial pressures of 4, 7, 10, and 13 bar and at corresponding saturation temperatures of octane. The biofuel products were characterized using GC-MS, LC-MS, FTIR spectroscopy, H-NMR, Higher heating values (HHV) and viscometer for comparison with those of commercial diesel fuel. Analysis of the lower molecular weight fractions of biofuels by GC-MS found that the hydrogenation reactor at pressures at 4 and 7 bar produced biofuels with predominant hydrocarbon contents of cycloalkanes and alkanes, while that at 10 and 13 bar produced biofuels with predominant contents of alkanes and alkenes. In comparison, diesel fuel contains mostly alkanes and aromatics. However, analysis over the whole content of bio-oil by H-NMR found that different pressures of reactor hydrogenation did not reduce alkene compositions in biofuels appreciably from alkene composition in bio-oil feed. In comparison, diesel fuel contained mostly alkanes with aromatic composition about $4 \%$ and no alkene content. Various data suggest that alkene content in the biofuels be reduced to approach their viscosity to that of diesel fuel. Modification of the hydrogenation reactor is required by improving convective momentum of hydrogen gas into the bio-oil to enhance contact of solid catalyst, hydrogen gas and bio-oil.
\end{abstract}

\section{Introduction}

The depletion of fossil fuels and the environmental consequences of its usage has stimulate the research about renewable fuels. One such example of renewable fuels is liquid biofuel. Liquid biofuel can be synthesized in many ways, one of which is the pyrolysis of biomass.

Pyrolysis of biomass produces non-condensable gas, liquid bio-oil and char. Bio-oil is a promising substance that could be a main substitute to liquid fossil fuel for transportation and electricity generation. But its low calorific value, corrosiveness and chemical instability caused by high content of oxygenate dictates that an upgrading is necessary if it will be used for its intended usage [1]. One particular method for upgrading bio-oil produced from biomass pyrolysis is via hydrodeoxygenation, in which bio-oil is reacted with high pressure hydrogen at elevated temperature [2].

A study by Supramono et al. [3] shows that in slow co-pyrolysis of corn cobs and polypropylene in a stirred tank reactor with $\mathrm{N}_{2}$ as a carrier gas, synergetic effect occurs. The synergetic effect includes producing higher yield of bio-oil compared to that of the combined bio-oil produced by pyrolysis of pure biomass and pure polypropylene. The other result of this synergetic effect is the reduction of oxygenated compound content in the biooil promoted by introduction of hydrogen radicals donated by polypropylene pyrolysis which substitute oxygen in bio-oil molecules. The stirred tank reactor configuration allows phase separation between polar and non-polar compounds of bio-oil caused by asymmetric viscosity between the two and by average low viscosity. This low viscosity is achieved as a result of enhanced convection heat transfer due to the presence of $\mathrm{N}_{2}$ bubble turbulence in the plastic melt [4].

Hydrodeoxygenation process of fatty acids to form biofuel undergoes 3 main reactions, i.e. decarbonylation, decarboxylation, and hydrogenation. Decarbonylation involves breaking of $\mathrm{C}-\mathrm{C}$ bonds in fatty acids which release $\mathrm{CO}$ gas. Decarboxylation involves 2 steps, mainly the dissociation of fatty acids into $\mathrm{H}$ cations and carboxylate anions and the breaking of $\mathrm{R}-\mathrm{CO}_{2}$ bonds by

* Corresponding author: mnasikin@che.ui.ac.id 
high temperature pyrolysis. Hydrogenation involves the saturation of double bonds in hydrocarbon compounds [5]. By phase separation of bio-oil into polar (oxygenated content) and non-polar (non-oxygenated content) fractions in co-pyrolysis of biomass and polypropylene in the present work, the upgrading of non-polar fraction of bio-oil only involves hydrogenation reaction thus reducing the load of catalytic process. The aim of the present work is to reduce the alkene content in the separated non-polar fraction of bio-oil by catalytic hydrogenation to obtain biofuel with low alkene content and viscosity approaching to that of diesel fuel.

In the present study of hydrogenation of non-polar fraction of bio-oil, nickel-molybdenum (NiMo) catalyst was chosen because of its selectivity towards hydrogenation reaction [6]. Carbon was used as the catalyst support to increase the contact area between the molecules and catalyst, to increase its thermal stability and hence the catalyst life [7]. Because of its non-acidic property, C-C cleavage was expectedly inhibited so that the molecular weight distribution may not change after hydrogenation [8].

\section{Materials and Methods}

\subsection{Materials}

Corn cobs were obtained from East Java and dried until the water content reached $10 \%$. Polypropylene beads were bought from a petrochemical company in West Java. $\left(\mathrm{NH}_{4}\right)_{6} \mathrm{Mo}_{7} \mathrm{O}_{24} .4 \mathrm{H}_{2} \mathrm{O}$ and $\mathrm{Ni}\left(\mathrm{NO}_{3}\right)_{2} .6 \mathrm{H}_{2} \mathrm{O}$ as chemical sources of catalyst and activated carbon for catalyst support were bought from Merck. NiMo/C catalyst prepared contains $5 \%$ weight of $\mathrm{NiMo}$, with the mole ratio of Ni to Mo 1:4. The method of producing this catalyst is discussed elsewhere [7]. Nitrogen gas was used as carrier gas in co-pyrolysis and hydrogen gas as a reactant in hydrogenation reaction.

\subsection{Methods}

Biofuel was synthesized through 2 stages, i.e. thermal copyrolysis of dried, chopped corn cob particles with polypropylene beads in a stirred tank reactor to produce bio-oil, and hydrogenation of non-polar fraction of bio-oil using catalyst $\mathrm{NiMo} / \mathrm{C}$ in a pressurised stirred tank reactor to produce biofuel. The co-pyrolysis process was conducted at a low heating rate $\left(5^{\circ} \mathrm{C} /\right.$ minute $)$ from ambient temperature to $500^{\circ} \mathrm{C}$. The feed composition ratio for the co-pyrolysis process of corn-cobs to polypropylene was $12.5: 87.5 \%$ mass. The reason of using this composition was because the non-polar fraction of bio-oil obtained from co-pyrolysis at various feed compositions showed no significant composition differences [3]. The use of separated non-polar bio-oil as a reactant in hydrogenation reaction removes unnecessary load of hydrogen gas for hydrogenation of oxygenated compounds. Fig. 1 shows a schematic diagram of the apparatus used for co-pyrolysis.

The hydrogenation experiment was conducted in a 330 $\mathrm{mL}$ semi-batch reactor enclosed with a cylindrical furnace. Extensive stirring of the non-polar bio-oil and the solid catalyst in the reactor was achieved using a stirrer driven by a DC geared motor. The weight ratio of catalyst $\mathrm{NiMo} / \mathrm{C}$ to the bio-oil catalyst was $100: 1$. Nitrogen gas was also used for purging the feed for 30 minutes prior to hydrogenation. The stirrer speed during the reaction was kept constant at $800 \mathrm{rpm}$. The hydrogenation reaction was carried out at various $\mathrm{H}_{2}$ initial pressures of $4,7,10$, and 13 bar with reaction temperature equal to the saturation temperature of octane at the corresponding pressures, i.e. $184,214,235$, and $253^{\circ} \mathrm{C}$, respectively. Each run was conducted for 90 minutes. The reaction time was started as the inside temperature of the reactor had reached the saturation temperature. Fig. 2 shows a schematic diagram of the hydrogenation experiment apparatus.

Effect of pressure and its corresponding saturation temperature of octane as the lowest molecular weight component in the biofuel composition in the hydrogenation reaction would be investigated by analysing bio-oil as feed to the hydrogenation reactor and biofuel produced using Gas Chromatography-Mass Spectroscopy (GC-MS), Liquid Chromatography-Mass Spectroscopy (LC-MS), Fourier- Transform Infra-Red (FTIR) spectroscopy, Hydrogen Nuclear Magnetic Rsonance (H-NMR) and viscometer. Higher Heating values of bio-oi, biofuels and commercial diesel fuel were predicted using Eq. 1 (see Section 3.3) based on H-NMR data.

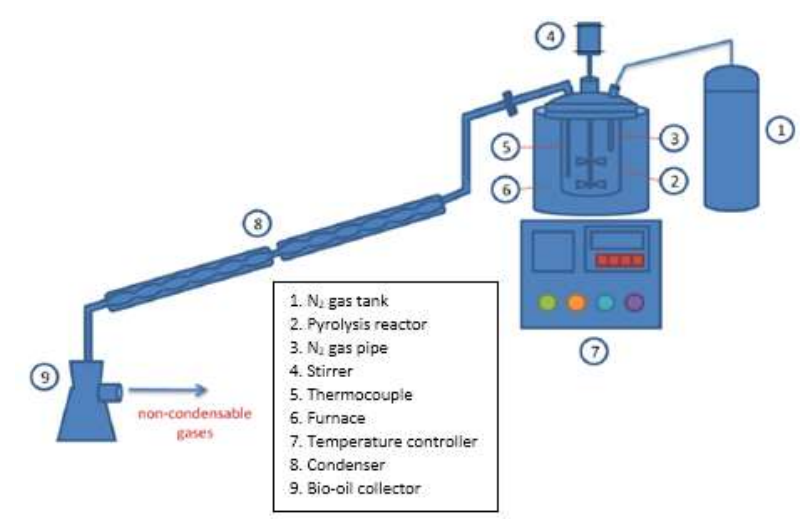

Fig. 1. Schematic Diagram of Co-Pyrolysis Apparatus

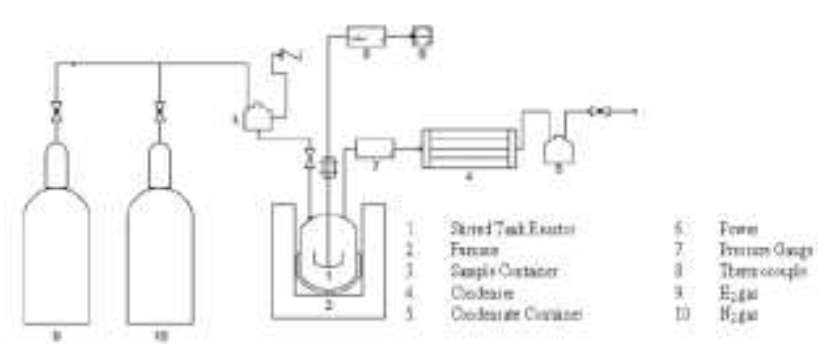

Fig. 2. Schematic Diagram of Hydrogenation Apparatus 


\section{Results and Discussion}

\subsection{Composition of bio-oil and biofuels}

Results of GC-MS analysis of carbon backbone chains in non-polar bio-oil from the co-pyrolysis reactor and biofuels from the hydrogenation reactor at various pressures are provided in Fig. 3. The figure shows that compared to the results of GC-MS analysis of the bio-oil as the feed of the hydrogenation reaction, at the hydrogenation pressure of 4 bar, the compositions of cycloalkanes improved and alkanes in the biofuel slightly improved, whereas at 7 bar, the compositions of alkanes increased and that of cycloalkanes slightly improved. At both pressures, the composition of alkenes dropped to minute amount. At higher pressures, i.e. 10 and 13 bar, alkanes, alkenes and cycloalkanes prevailed in the biofuels with various composition patterns.

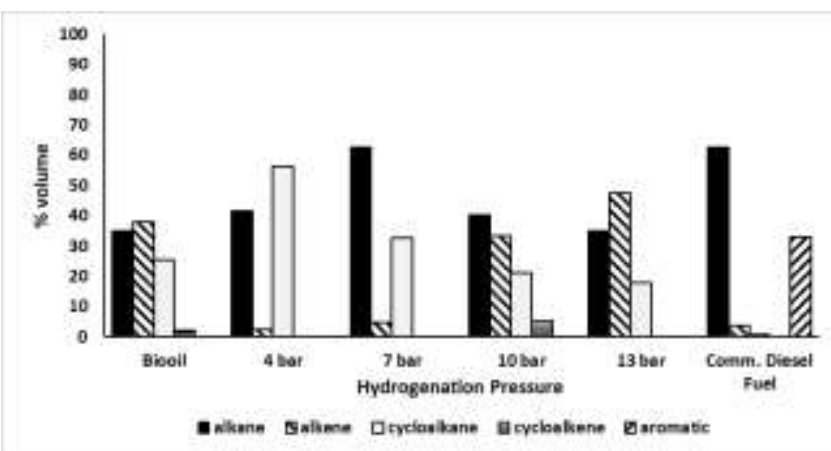

Fig. 3. GC-MS analysis results of bio-oil and biofuels at various hydrogenation pressures

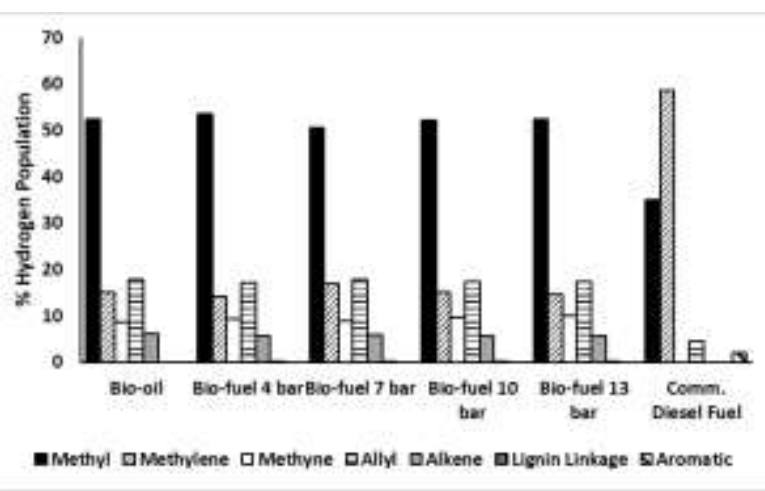

Fig. 4. H-NMR analysis results of bio-oil and biofuels at various hydrogenation pressures

Analysis results of hydrogen contents of different chemical bonds in bio-oil and biofuels at various hydrogenation pressures by H-NMR are provided in Fig. 4. Fig. 4 shows that there were no significant changes of hydrogen compositions between the bio-oil and the biofuels in different chemical bonds. This fact is supported by FTIR spectra of the bio-oil and the biofuels at different hydrogenation pressures shown in Fig. 5. All peaks belonging to all bio-oil and biofuels are shown in Table 1. The FTIR spectra show no significant differences of chemical bond intensities of bio-oil and biofuels.
Sharypov et al [9] Nanda et al [10] found that GC-MS is not capable of analysing molecules with low volatility. Agilent GC-MS measuring equipment has a capability of mass acquisition over the range 50-550 [11], (only part of bio-oil) while H-NMR analysed all hydrogen atoms attributed to all molecular weight compounds in the biooil or biofuel. Comparison of Fig. 3 and 4 gives indication that only part of bio-oil, which composed low molecular weight compounds, was sensible to the pressure variation in the hydrogenation reactor. To this part of the bio-oil, pressures of 4 and 7 bar increased alkane and cycloalkane compositions and dropped alkene composition compared to those in bio-oil, while at pressures of 10 and 14 bar, compositions of alkanes, cycloalkanes and alkenes were different from those in bio-oil in various patterns. To the whole content of bio-oil, H-NMR analysis found that only about $6 \%$ mole of $\mathrm{H}$ was attributed to alkene compounds. The rest of the bio-oil content, which mostly contained methyl $\mathrm{H}$, methylene $\mathrm{H}$, methane $\mathrm{H}$ and allyl $\mathrm{H}$, was attributed to saturated carbon chains. Therefore, by GCMS, types of chemical chains whether alkanes, alkenes, cycloalkanes, cycloalkenes and aromatics in small molecular weight compounds can be identified, but by HNMR, compositions of $\mathrm{H}$ attributed to various chemical chains can be quantified. Data of H-NMR subsequently can be used to estimate weight compositions of saturated and unsaturated carbon chains as well as of aromatic rings.

Table 1. FTIR analysis results of bio-oil and biofuels at various hydrogenation pressures

\begin{tabular}{|c|c|c|}
\hline $\begin{array}{c}\text { Wavenumber } \\
(\mathbf{c m}-\mathbf{1})\end{array}$ & Intensity & $\begin{array}{c}\text { Functional } \\
\text { group/assignment }\end{array}$ \\
\hline 3074 & medium & alkene $(\mathrm{C}=\mathrm{C}-\mathrm{H})$ \\
\hline 2955 & strong & $\begin{array}{c}\text { Methyl }(\mathrm{C}-\mathrm{H}) \text { asymmetric } \\
\text { stretch }\end{array}$ \\
\hline 2910 & strong & $\begin{array}{c}\text { methyne }(\mathrm{C}-\mathrm{H}) \\
\text { asymmetric stretch }\end{array}$ \\
\hline 2871 & medium & $\begin{array}{c}\text { methyl }(\mathrm{C}-\mathrm{H}) \text { symmetric } \\
\text { stretch }\end{array}$ \\
\hline 2839 & medium & methyl $(\mathrm{C}-\mathrm{H})$ \\
\hline 1649 & medium & alkene conjugated \\
\hline 1456 & medium & $\begin{array}{c}\text { methyl (C-H) asymmetric } \\
\text { stretch }\end{array}$ \\
\hline 1376 & medium & gem-dimethyl \\
\hline 971 & medium & cyclohexane \\
\hline 886 & strong & alkene (vinyl) \\
\hline
\end{tabular}

By referring to GC-MS analysis (Fig. 3) and H-NMR analysis (Fig. 4), for comparison of bio-oil and biofuel against commercial diesel fuel, in low molecular weight diesel fuel, aromatics content in the fuel was about $30 \%$, majority of which were naphthalene and its derivatives. However, this composition dropped to about $4 \%$ in the whole content of oil. On the other hands, all bio-oil and biofuel did not contain aromatic compounds. Related to the aim of the present work, Fig. 4 reveals that the intended hydrogenation reaction was unable to reduce the alkene composition in the biofuel significantly. In fact, the composition was similar under different reactor pressures. 


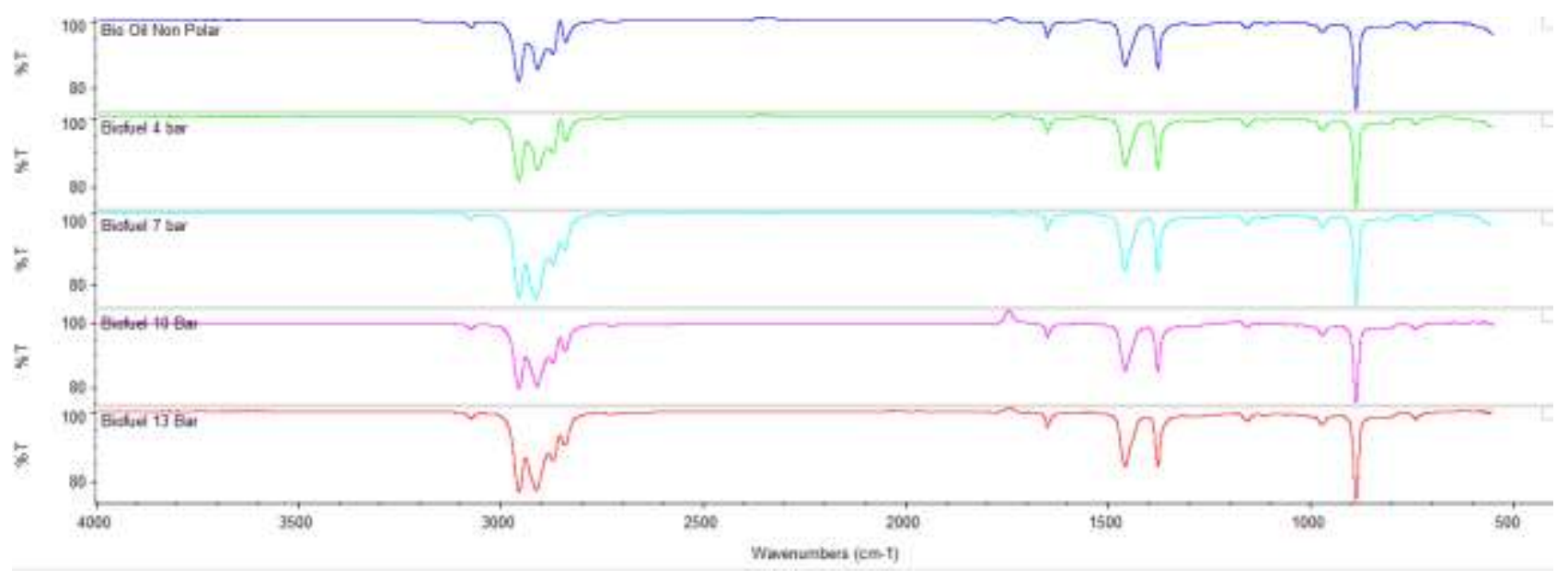

Fig. 5. FTIR analysis results of bio-oil and biofuels at various hydrogenation pressures

This may be attributed to the high resistance of hydrogen mass diffusion from the gas phase into the liquid phase of bio-oil [12]. Because hydrogen pipe to the reactor had inlet point on the reactor lid, the hydrogen gas just settled on the upper part of the reactor above the liquid phase. It seems that the contact between the catalyst, hydrogen gas and bio-oil occurred on the surface of bio-oil, which depended on the circulation rate of bio-oil driven by the impeller rotation.

\subsection{Proposed means of better contacting hydrogen gas to bio-oil}

To achieve appropriate contact between the catalyst particle (solid phase), hydrogen gas and bio-oil (liquid phase), it requires sufficient momentum of hydrogen gas into the bio-oil. In this case, the impeller should have taken the role. The stirrer used has an impeller with 4 blades. The blade type used was made of flat paddles, which induced a high radial velocity fluid flow and not the axial flow [13]. The blade type and the mixing pattern are shown at Fig. 6 and Fig. 7 respectively. In order to transport catalyst particles across the whole volume of bio-oil, the bio-oil convection flow should have been generated by high pumping rate to avoid the settling of the particles. However, the high stirrer rotation to generate high pumping rate may have promoted the formation of vortex in the centreline of the cylindrical reactor due to no baffles installed on the reactor wall [13]. The presence of the vortex adversely reduced the pumping rate of the liquid and consequently reduced the inducement of hydrogen gas into liquid phase [14]. This resistance of hydrogen mass transport from the gas phase into the liquid phase of bio-oil caused less frequent contact time between the hydrogen gas and the solid catalyst as prerequisite of the hydrogenation reaction [15]. It seems that this little contact caused no appreciable reaction between hydrogen and alkenes in bio-oil feed and in biofuels at different pressures as shown in Fig. 4. The installation of baffles on the other hand would generate a problem of convective heat transfer from the reactor wall into the bio-oil.

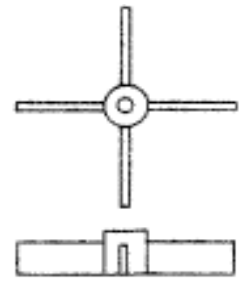

Fig. 6. Flat blade paddle impeller [13]

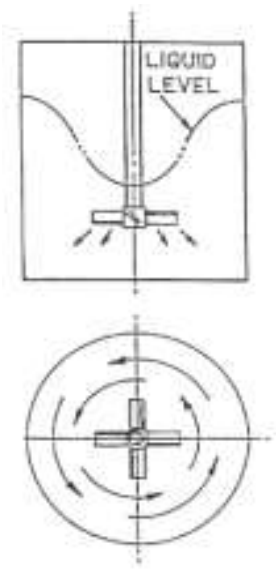

Fig. 7. Flat paddle impeller mixing pattern. The highest velocity component is the tangential ones, with low axial velocity component [13]

Referring to arguments above, it seems to be difficult to let hydrogen gas diffuse into the liquid phase by residing the gas in the upper part of the reactor. One means of improving the contact between 3 phase materials of hydrogen gas, liquid phase and catalyst particles may be by extending the hydrogen pipe into the lower part of the reactor and replacing the current impeller with down pumping pitched $60^{\circ}$-blade turbine type [16]. This new impeller can generate high axial flow of bio-oil, dispersion of the hydrogen gas throughout bio-oil [16], high fluctuation of mean instantaneous velocity in the biooil, high vorticity and shear strain in the downflow [17]. High fluctuation of velocity, high vorticity and shear strain are favourable for contacting 3 phases of material, i.e. solid catalyst, hydrogen gas and bio-oil.

\footnotetext{
* Corresponding author: mnasikin@che.ui.ac.id
} 


\subsection{Higher heating value (HHV) of bio-oil and biofuels}

The availability of H-NMR data allows prediction of higher heating value of bio-oil and biofuels obtained from the hydrogenation reactor. A correlation of higher heating value (HHV) calculation proposed by Channiwala and Parikh [18] to quantify the HHV of bio-oil and biofuels is as follows

$$
\begin{array}{r}
H H V=0.3491 C+1.1783 H+0.1005 S-0.1034 O-0.0151 N- \\
0.0211 \mathrm{~A}(\mathrm{MJ} / \mathrm{kg})
\end{array}
$$

where $C, H, S, O, N$ and $A$ are the mass fraction of atoms carbon, hydrogen, sulphur, oxygen, nitrogen and ash, respectively.

The results of HHV calculations of bio-oil, biofuels and commercial diesel fuel are shown in Fig. 8. The figure shows that hydrogenation pressures almost had no effect on HHV values. The value of diesel fuel was higher than those of bio-oil and biofuels because the diesel fuel contains aromatic group, which has higher mole ratio of carbon to hydrogen (see Fig. 4).

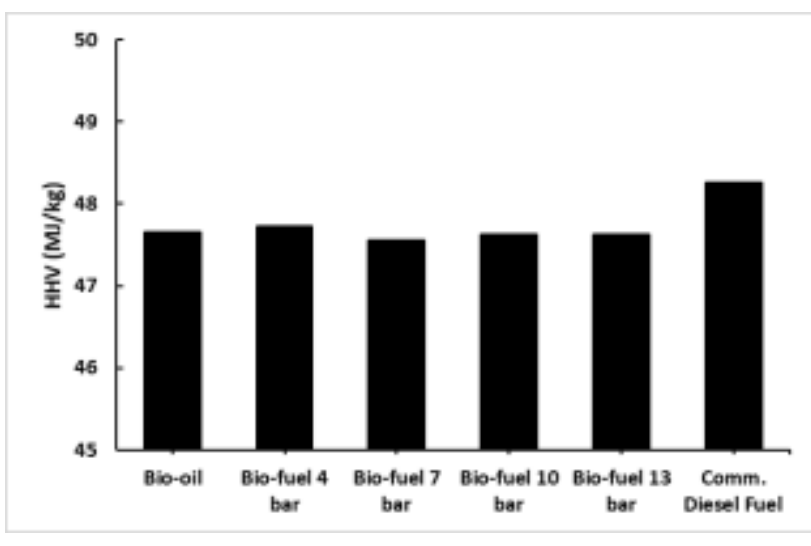

Fig. 8. Higher Heating Values of bio-oil and biofuels at various hydrogenation pressures predicted using Eq. 1.

\subsection{Viscosity of bio-oil and biofuels}

Viscosity is an important parameter for diesel fuel because it influences the quality of atomization of the fuel to achieve good mixing of air-fuel and the formation of deposit in the engine [19]. The viscosities of bio-oil and biofuels are exhibited in Fig. 9. It shows that biofuel obtained from the hydrogenation under 10 bar had the highest kinematic viscosity of $3.3 \mathrm{cSt}$, while commercial diesel fuel $2.2 \mathrm{cSt}$, the lowest compared to those of biooil and biofuels. The value of viscosity is influenced by branching index [20], alkene content [21] and molecular weight distribution. The branching index is a measure how extent is the branching of molecules occurs in a carbon backbone chain. It is calculated using H-NMR data and by Eq. 2 [22] as follows

$$
B I=\frac{\left[\left(\frac{1}{3}\right) S_{\mathrm{CH}_{3}}\right]}{\left(\frac{1}{2}\right)\left(S_{\mathrm{CH}_{2}}+S_{\mathrm{CH}}\right)}
$$

where $\mathrm{S}_{\mathrm{CH}_{3}} \mathrm{~S}_{\mathrm{CH}_{2}}$ and $\mathrm{S}_{\mathrm{CH}}$ are $\%$ amount of protons in $\mathrm{CH}_{3}$, $\mathrm{CH}_{2}$ and $\mathrm{CH}$, respectively. Higher $B I$ value indicates that the carbon chain has more number of branches but shorter branches [23].

Comparison of branching indices between commercial diesel fuel against bio-oil and biofuels calculated using Eq. 2 based on data extracted from Fig. 4 shows that bio-oil and biofuels had higher indices of branching compared to that of diesel fuel. This indicates that bio-oil and biofuels had high degree of branching indicated by high content of methyl, whereas commercial diesel fuel contained mostly linear hydrocarbons with lesser degree of branching indicated by more content of methylene. Fig. 4 also indicates that bio-oil and biofuels had higher contents of vynil (alkenes) compared to that of diesel fuel. Lesser degree of branching and lower contents of vynilic content in diesel fuel respectively enhances the oil viscosity [20] and attenuates the oil viscosity [21]. Molecular weight distribution measured by LC-MS and shown in Fig. 10 suggests that diesel fuel would exhibit viscosity similar to that of biofuel prepared by the hydrogenation reaction at 7 bar. In fact, the earlier had viscosity lower than that of the latter. Looking at all factors influencing the viscosity of bio-oil, biofuels and diesel fuel, it can be implied that very low content of alkenes was more determinant of achieving low viscosity in diesel fuel.

In terms of ignition delay time, very low content of alkenes in diesel fuel has benefit of achieving earlier ignition [24]. Fuel with low content of alkenes inhibits the formation of high molecular weight molecules, which induces earlier self-ignition and benefits for diesel engine performance.

Distribution of \%area of bio-oil and biofuels over wide range of $\mathrm{m} / \mathrm{z}$ shown in Fig. 10 and viscosity of biooil and biofuels shown in Fig. 9 may reveal how polymerization and cracking occurred during hydrogenation reactions. Vinu et al [25] have predicted the occurrence of co-reaction of polymerization and cracking of alkenes when they were heated to about $300^{\circ} \mathrm{C}$. Fig. 9 shows that that viscosity increased as the hydrogenation pressure was increased until the pressure reached 10 bar. This indicates that there may have been polymerization of alkenes. Fig. 10 shows that biofuels in the reactor at the pressures of 7 and 10 bar compared to bio-oil exhibited higher \%area at lower $\mathrm{m} / \mathrm{z}$ 's and the spreading of \%area to high $\mathrm{m} / \mathrm{z}$, i.e. 1000 , and 900 respectively beyond the highest $\mathrm{m} / \mathrm{z}$ of bio-oil, i.e. 700 . The higher \%area at lower $\mathrm{m} / \mathrm{z}$ 's indicates that under the pressures of 7 and 10 bar, bio-oil underwent cracking to form smaller molecules and the presence of molecules with high $\mathrm{m} / \mathrm{z}$ indicates that polymerization have occurred during hydrogenation at pressures of 7 and 10 bar.

In case of biofuels obtained from hydrogenation at pressures of 4 and 13 bar compared to bio-oil, their highest $\mathrm{m} / \mathrm{z}$ was nearly the same of that of bio-oil, i.e. 700, but higher \%area occurred at higher $\mathrm{m} / \mathrm{z}$ 's for biofuel formed at 4 bar, and higher \%area occurred at lower $\mathrm{m} / \mathrm{z}$ 's for biofuel formed at $13 \mathrm{bar}$. Higher \%area at higher m/z's and at lower $\mathrm{m} / \mathrm{z}$ 's indicates there was polymerization and cracking, respectively. The occurrence of cracking at 13 bar is also indicated by GC-MS data (see Fig. 3) by high composition of low molecular weight alkenes in biofuel 
and this made viscosity of biofuel formed at 13 bar lower than that at 10 bar.

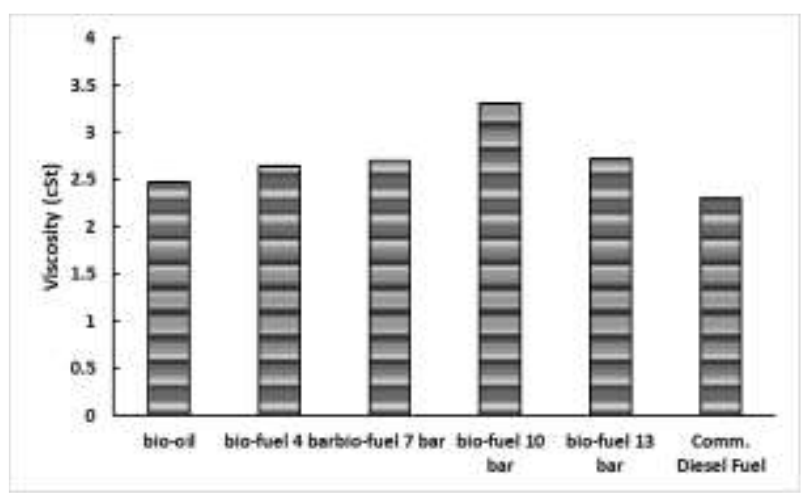

Fig. 9. Viscosity analysis results of bio-oil and biofuels at various hydrogenation pressures.

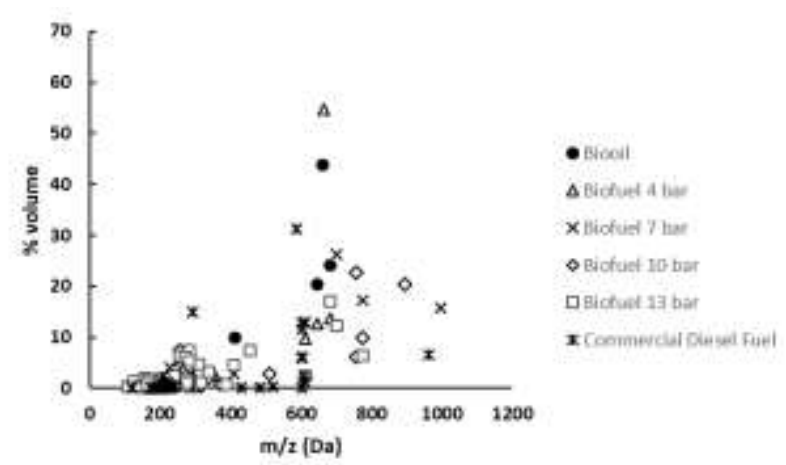

Fig. 10. LC-MS analysis results of bio-oil and biofuels at various hydrogenation pressures

\section{Conclusions}

Analysis of lower molecular weight fractions of biofuels by GC-MS found that alkane and cycloalkane formation in hydrogenation reactor was favourable at lower pressures, i.e. 4 and 7 bar. However, the hydrogenation reaction at pressures of 10 and 13 bar produced biofuels with predominant component alkanes and alkenes. In comparison, diesel fuel contains mostly alkanes and aromatics. Analysis over the whole content by H-NMR found different pressures of reactor hydrogenation did not reduce alkene compositions in biofuels appreciably compared to alkene composition in bio-oil feed. In comparison, diesel fuel mostly contained alkanes with aromatic composition about $4 \%$ and no alkene content. Various data suggest that alkene content in the biofuels be reduced to approach their viscosity to that of diesel fuel.

The authors would like to express their gratitude to Universitas Indonesia for its financial support through PITTA (Publikasi Terindeks Internasional untuk Tugas Akhir Mahasiswa) scheme with contract number 2483/UN2.R3.1/HKP.05.00/2018 for the budget year 2018. The authors also would like to express their high appreciation to Dr Bambang Heru Susanto of the Department of Chemical Engineering, Universitas Indonesia, for his permission to use his reactor for the present work.

\section{References}

1. Q. Lu, W. Li, X. Zhu. Overview of Fuel Properties of Biomass Fast Pyrolysis Oils. Energy Conv. \& Man. 50, 1377 (2009)

2. Y. Liu, R. Sotelo-Boyas, K. Murata, T. Minowa, K. Sakanishi. Hydrotreatment of Vegetable Oils to Produce Bio-hydrogenated Diesel and Liquefied Petroleum Gas Fuels over Catalysts Containing Sulfided Ni-Mo and Solid Acids. Energy \& Fuels. 25, 4677 (2011)

3. D. Supramono, Jonathan, Haqqyana, Setiadi, M. Nasikin. Improving Bio-oil Quality through Copyrolysis of Corn Cobs and Polypropylene in a Stirred Tank Reactor. International Journal of Technology (2016) 8, 1381 (2016)

4. D. Supramono, Julianto, Haqqyana, Setiadi, M. Nasikin. Phase Separation of Bio-oil Produced by Co-pyrolysis of Corn Cobs and Polypropylene. IOP Conf. Series: Earth and Environmental Science 93 (2017) 012072

5. X. Li, X. Luo, Y. Jin, J. Li, H. Zhang, A. Zhang, J. Xie. Heterogeneous Sulphur-Free Hydrodeoxygenation Catalysts for Selectively Upgrading the Renewable Bio-oils into Second Generation Biofuels. Ren. \& Sust. En. (to be published)

6. D. Kubička, L. Kaluža. Deoxygenation of Vegetable Oils under Sulfided Ni, Mo and NiMo Catalysts. Appl. Catal. A-Gen. 372, 199-208 (2010).

7. B.H. Susanto, M.B. Prakasa, M.H. Shahab. Preparation and Characterization of $\mathrm{NiMo} / \mathrm{C}$ using Rapid Heating and Cooling Method for Renewable Diesel Synthesis from Nyamplung Oil (Calophyllum Inophyllum Oil). International Series of Interdisciplinary Science and Technology 1, 43 (2017)

8. R. Maggi, B. Delmon. A Review of Catalytic Hydrotreating Processes for the Upgrading of Liquids Produced by Fast Pyrolysis. Hydro. Treat. and Hydro Crack. Oil Fract. 1, 99-112 (1997)

9. V.I. Sharypov, N.G. Beregovtsova, B.N. Kuznetsov, L. Membrado, V.L. Cebolla, N. Marin, J.V. Weber. Co-pyrolysis of Wood Biomass and Synthetic Polymers Mixtures. Part III: Characterisation of Heavy Products. J. Anal. Appl. Pyrolysis. 67, 333 (2003)

10. S. Nanda, P. Mohanty, J.A. Kozinski, A.K. Dalai. Physico-Chemical Properties of Bio-oils from Pyrolysis of Lignocellulosic Biomass with High and Slow Heating Rate. Energy and Env. Res. 4, 27 (2014)

11. B. Kunwar, S.D. Deilami, L.E. Macaskie, J. Wood, P. Biller, B.K. Sharma. Nanoparticles of Pd Supported on Bacterial Biomass for Hydroprocessing Crude Bio-oil. Fuel 209, 450 (2017)

12. F. Nerozzi. Heterogeneous Catalytic Hydrogenation. Platinum Metals Rev. 56, 238 (2012) 
13. R. Coulson, J.F. Richardson. Chemical Engineering Vol. 1: Fluid Flow, Heat and Mass Transfer. Butterworth \& Heinemann (1993)

14. A. Busciglio, F. Grisafi, F. Ippolito, F. Scargiali, A. Brucato, Mixing Time in Unbaffled Stirred Tanks. $14^{\text {th }}$ European Conference on Mixing, Warszawa (2012).

15. M. Hudlicky. Reductions in Organic Chemistry, 2nd edition. American Chemical Society, p. 429 (1996)

16. R. Achouri, I. Mokni, H. Mhiri, P. Bournot, A 3D CFD Simulation of a Self-inducing Pitched Blade Turbine Downflow. Energy Conversion and Management 64, 633-641 (2012).

17. B.B. Amira, Z. Driss, M.S. Abid, PIV Study of a $45^{\circ}$ Piched Blade Turbine: Up and Down-Pumping Direction Effect on the Hydrodynamic Structure in a Stirred Tank. International Journal of Mechanics and Applications 3(4), 88-97 (2013,)

18. S.A. Channiwala, P.P. Parikh. A Unified Correlation for Estimating HHV of Solid, Liquid and Gaseous Fuels. Fuel. 81, 1051-1053 (2002).

19. G. Knothe, J.V. Gerpen, J. Krahl, L.P. Ramos. The Biodiesel Handbook. Blucher, Sao Paulo, pp. 89-90 (2006)

20. R. Khare, J. de Pablo. Rheological, Thermodynamic, and Structural Studies of Linear and Branched Alkanes under Shear. J. Chem. Phys., 107, 6956 (1997)

21. L. Ingram, D. Mohan, M. Bricka, P. Steele, D. Strobel, D. Crocker, B. Mitchell, J. Mohammad, K. Cantrell, C.U. Pittman, Jr.. Pyrolysis of Wood and Bark in an Auger Reactor: Physical Properties and Chemical Analysis of the Produced Bio-oils. Energy \& Fuels 22, 614-625 (2008).

22. G. Yan, X. Jing, H. Wen, S. Xiang. Thermal Cracking of Virgin and Waste Plastics of PP and LDPE in a Semibatch Reactor under Atmospheric Pressure. Energy \& Fuels, 29, 2289 (2015).

23. D.V. Naik, V. Kumar., B. Prasad, M.K. Poddar, B. Behera, R. Bal, O.P. Khatri, D.K. Adhikari, M.O. Garg. Overview of Fuel Properties of Biomass Fast Pyrolysis Oils. Energy Conversion and Management, 5, 389 (2015).

24. A.G.A. Jameel, N. Naser, A. Emwas, S. Dooley, S.M. Sarathy. Predicting Fuel Ignition Quality using 1HNMR Spectroscopy and Multiple Linear Regression. Energy \& Fuels, 30, 11 (2016)

25. R. Vinu, L.J. Broadbelt, Unraveling Reaction Pathways and Specifying Reaction Kinetics for Complex Systems. Annu. Rev. Chem. Biomol. Eng., 3, 29-54 (2012) 